\title{
Risk factors and outcomes for pandemic H1N1 influenza compared with seasonal influenza in hospitalized children in China
}

\author{
Qingli Zhang MD¹, Wei Ji MD², Zhongqin Guo PD ${ }^{3}$, Zhenjiang Bai MD ${ }^{1}$, Noni E MacDonald MD ${ }^{4}$
}

Q Zhang, W Ji, Z Guo, Z Bai, NE MacDonald. Risk factors and outcomes for pandemic H1N1 influenza compared with seasonal influenza in hospitalized children in China. Can J Infect Dis Med Microbiol 2012;23(4):199-203.

OBJECTIVE: To compare clinical features and outcomes of children hospitalized in China with pandemic (p)H1N1 between 2009 and 2010 versus seasonal influenza A between 2008 and 2009.

METHODS: Systematic review of laboratory-confirmed admissions to the Children's Hospital, Soochow University (Suzhou, China).

RESULTS: Seventy-five children younger than 14 years of age were admitted with pH1N1, 70 with H3N2 and three with seasonal H1N1. With pH1N1, the mean age was older (36 months versus seven months), the length of stay was longer (nine days versus seven days), underlying conditions were more common (29\% versus $15 \%$ ), anemia was more common $(11 \%$ versus $0 \%)(\mathrm{P}<0.05)$, with trends toward more secondary bacterial pneumonia and intensive care unit care, compared with seasonal influenza. Two of the 75 children with pH1N1 died versus no deaths in children with seasonal influenza. None of the children had received $\mathrm{pH} 1 \mathrm{~N} 1$, seasonal influenza, conjugated pneumococal or Haemophilus influenzae b vaccines.

CONCLUSION: In China, children hospitalized with pH1N1 influenza differed from case series in Canada, Argentina and the United States, suggesting that locale, background and health care system influenced the presentation and outcomes of pandemic and seasonal influenza.

Key Words: Children; China; Influenza; Pandemic; Seasonal

\section{Les facteurs de risque et les issues de la pandémie de grippe $\mathrm{H} 1 \mathrm{~N} 1$ par rapport à l'influenza saisonnière chez des enfants hospitalisés en Chine}

OBJECTIF : Comparer les caractéristiques cliniques et les issues d'enfants hospitalisés en Chine en raison de la pandémie de grippe (p)H1N1 entre 2009 et 2010 à ceux hospitalisés à cause de l'influenza A saisonnière entre 2008 et 2009.

MÉTHODOLOGIE : Analyse systématique des hospitalisations confirmées en laboratoire à l'hôpital universitaire pour enfants de Suzhou, en Chine RÉSULTATS : Soixante-quinze enfants de moins de 14 ans ont été hospitalisés en raison de la grippe $\mathrm{pH} 1 \mathrm{~N} 1,70$, en raison de la grippe $\mathrm{H} 3 \mathrm{~N} 2$ et trois, de l'influenza saisonnière H1N1. En cas de grippe pH1N1, les patients avaient un âge moyen plus élevé (36 mois par rapport à sept), étaient hospitalisés plus longtemps (neuf jours plutôt que sept), étaient plus souvent atteints de maladies sous-jacentes (29\% par rapport à $15 \%$ ) ou d'anémie $(11 \%$ plutôt que $0 \%)(\mathrm{P}<0,05)$ et présentaient une tendance vers un plus grand nombre de pneumonies bactériennes secondaires et de séjours à l'unité de soins intensifs que ceux ayant une influenza saisonnière. Deux des 75 enfants sont décédés de la grippe pH1N1, mais aucun de l'influenza saisonnière. Aucun des enfants n'avait reçu le vaccin contre la grippe pH1N1, contre l'influenza saisonnière ou contre l'Haemophilus influenzae de type b ou le vaccin conjugué contre le pneumocoque.

CONCLUSION : En Chine, les enfants hospitalisés en raison de la grippe pH1N1 étaient différents de la série de cas du Canada, de l'Argentine et des États-Unis, ce qui laisse croire que le lieu, l'historique et le système de santé influent sur la présentation et les issues de la grippe pandémique et de l'influenza saisonnière.
In spring 2009, the United States Centers for Disease Control and 1 Prevention (Georgia, USA) reported the occurrence of a novel 2009 influenza A strain pandemic (p)H1N1 in two children in southern California (1). Subsequently, infection with this new pandemic strain of virus was reported in virtually every country, with the largest numbers of confirmed cases documented in the United States, Mexico, Canada, Chile and Australia (2-6).

Not only is seasonal influenza a significant cause of morbidity and mortality in younger children, but school-age children are now well recognized as important vectors for the spread of influenza in the community $(7-10)$. With respect to illness due to $\mathrm{pH} 1 \mathrm{~N} 1$ in children, early case series reported only small numbers of children, often with mild illness and/or with child data that were not clearly distinguished from adult data (11-17). One case series involving 251 children in Argentina noted an overall mortality rate of 1.1 per 100,000 children with pH1N1 compared with 0.1 per 100,000 children with seasonal influenza in 2007, suggesting more severe illness in children with the pandemic strain (18). In contrast, a study by O'Riordan et al (19) from Toronto, Ontario, involving 58 children hospitalized with pH1N1 compared with 200 children hospitalized with seasonal influenza in the previous five years, did not find more severe disease associated with pH1N1. The mean age of the children admitted with $\mathrm{pH} 1 \mathrm{~N} 1$ was older than those admitted with seasonal influenza, older than the mean age reported from Argentina for $\mathrm{pH} 1 \mathrm{~N} 1$ but similar to that reported from a $140 \mathrm{pH} 1 \mathrm{~N} 1$ pediatric case series admitted in Baltimore (USA) (20). In the Baltimore study, $9 \%$ of the children required intensive care compared with $21 \%$ and $19 \%$ in Toronto and Argentina, respectively. It is unclear whether these differences in severity of illness reflect regional differences in the size and types of populations or reflect differences in other factors.

Data from China, a very different region, comparing the severity of illness in children hospitalized with pH1N1 with previous seasonal influenza years, as well as data on acute respiratory distress syndrome in these patients were unavailable. Therefore, we reviewed the cases of all children admitted to the Children's Hospital affiliated with Soochow University in Suzhou, China, with confirmed pH1N1 influenza compared with children admitted with seasonal influenza A H1N1 or H3N2 in 2008 and 2009. Our goal was to compare the severity of illness and outcomes between pH1N1 and seasonal influenza in this cohort, and to compare the findings for $\mathrm{pH} 1 \mathrm{~N} 1$ with those in the published cohorts from South America (Argentina [18]) and North America (Toronto [19] and Baltimore [20]).

\section{METHODS}

Using a standardized collection form, data were extracted from the charts of all children admitted to the Children's Hospital affiliated

${ }^{1}$ Pediatric Intensive Care Unit; ${ }^{2}$ Division of Respiratory Disease, Children's Hospital Affiliated with Soochow University, Suzhou, Jiangsu;

${ }^{3}$ Department of Public Health, Ningxia Medical University, Yinchuan, PR China; ${ }^{4}$ Department of Pediatrics, IWK Health Centre, Dalhousie

University, Halifax, Nova Scotia

Correspondence: Dr Noni E MacDonald, IWK Health Centre, 5850/5980 University Avenue, Halifax, Nova Scotia B3K 6 R8.

Telephone 902-470-8498, e-mail noni.macdonald@dal.ca. 


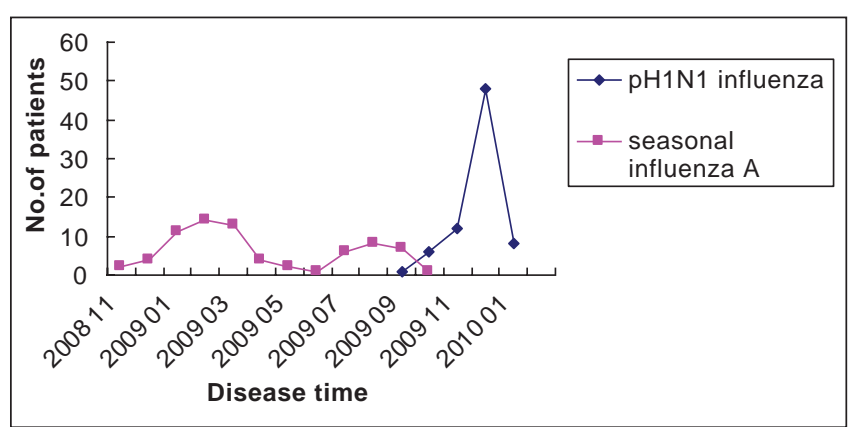

Figure1) Admission of confirmed cases of seasonal influenza and pandemic (p)H1N1 to the Children's Hospital affiliated with Soochow University, Suzhou, China, from November 1, 2008 to January 2010

with Soochow University with laboratory-confirmed pH1N1 influenza in 2009 and 2010. This hospital has 650 beds, an average yearly admission rate of approximately 30,000 and serves as the pediatric (younger than 14 years of age) referral centre for the Greater Suzhou Area and the surrounding region. There are 8.26 million people in Suzhou itself, with a pediatric population (zero to 14 years of age) of 1.2 million. Using the same collection form, data were extracted from the charts of all children admitted during 2008 and 2009 with laboratory-confirmed seasonal influenza A (H3N2 or nonpandemic H1N1).

All children admitted with influenza-like illness routinely had a pharyngeal swab sent to the Centers for Disease Control and Prevention in Suzhou for verification of the diagnosis by reverse transcription polymerase chain reaction testing for influenza A and B, using commercially available kits (Beijing Jinhao Company, China). Children who were in hospital for more than three days before the onset of influenza-like symptoms were excluded because these were deemed to more likely be nosocomial infections.

Definition of acute lung injury and acute respiratory distress syndrome

The consensus definitions of acute lung injury and acute respiratory distress syndrome reported by Bernard et al (21) were used. The criteria for acute lung injury are acute onset, a ratio of partial pressure of arterial oxygen to the fraction of inspired oxygen $\left(\mathrm{PaO}_{2} / \mathrm{FiO}_{2}\right)$ $<300 \mathrm{mmHg}$ (regardless of positive end-expiratory pressure [PEEP]), bilateral infiltrates seen on frontal chest radiograph, and a pulmonary artery wedge pressure $<18 \mathrm{mmHg}$ or no clinical evidence of left atrial hypertension. The criteria for acute respiratory distress syndrome is the same as for acute lung injury except that the $\mathrm{PaO}_{2} / \mathrm{FiO}_{2}<200 \mathrm{mmHg}$ (regardless of PEEP level).

\section{Diagnosis of secondary bacterial infection}

For children admitted to the pediatric intensive care unit with either pH1N1 or seasonal influenza who required intubation, lower respiratory secretions were obtained via suctioning through a freshly placed endotracheal tube and subsequently cultured. For hospitalized children who were not intubated, tracheal aspirates were obtained. These specimens were smeared, stained and examined in the laboratory, and followed by routine bacterial respiratory culture. Screening qualifications included an epithelial cell count of $<10$ per low-power field and a leukocyte count of $>25$ per low-power field.

\section{Data collection}

The data extracted from the charts included the following: demographic data; underlying medical conditions known to increase risk factors for influenza-related complications, such as cardiac or pulmonary disorders, diabetes mellitus and other metabolic diseases; cancer; immunodeficiency; immunosuppression; renal disease; anemia and hemoglobinopathies (22); micronutrient deficiency (eg, vitamin D deficiency and rickets [23]); clinical features at presentation; influenza-related complications; radiographical and laboratory findings; clinical course; and
TABLE1

Characteristics of children admitted to hospital with laboratory-confirmed pandemic H1N1 influenza (September 2009 to January 2010) and with seasonal H1N1 or H3N2 influenza A (November 1, 2008 to November 1, 2009)

\begin{tabular}{|c|c|c|c|}
\hline Characteristic & $\begin{array}{c}\text { Pandemic } \\
\text { H1N1 influenza } \\
(n=75)\end{array}$ & $\begin{array}{c}\text { Seasonal } \\
\text { influenza A } \\
(H 1 N 1, N 3 N 2) \\
(n=73)\end{array}$ & $\mathbf{P}$ \\
\hline Male sex & $46(61)$ & $44(60)$ & $>0.05$ \\
\hline Age, months, median (IQR) & $36(12-59.25)$ & $7(3-12)$ & $<0.05$ \\
\hline \multicolumn{4}{|l|}{ Age group, years } \\
\hline$<2$ & $30(40)$ & $71(97)$ & \\
\hline 2 to 5 & $27(36)$ & $2(3)$ & \\
\hline$>5$ & $18(24)$ & $0(0)$ & $<0.01$ \\
\hline \multicolumn{4}{|l|}{ Admitted to ICU } \\
\hline $\mathrm{n}$ & $18(24)$ & $13(18)$ & $>0.05$ \\
\hline Age, months, median (IQR) & $36(12-72)$ & $3(3-19)$ & $<0.01$ \\
\hline \multicolumn{4}{|l|}{ Required mechanical ventilation } \\
\hline All children & $12(16)$ & $3(4)$ & $>0.05$ \\
\hline Children admitted to ICU & $12(67)$ & $3(23)$ & $<0.05$ \\
\hline \multicolumn{4}{|l|}{ Length of stay, days (range) } \\
\hline In hospital without ICU care & $9(8-12)$ & $7(6-8)$ & $<0.01$ \\
\hline In ICU & $9(12-27)^{\star}$ & $3(8-12)^{\star}$ & $<0.01$ \\
\hline \multicolumn{4}{|l|}{ Underlying condition(s) } \\
\hline 0 & $57(76)$ & $62(85)$ & \\
\hline 0 & $14(19)$ & $11(15)$ & \\
\hline$\geq 2$ & $4(5)$ & $0(0)$ & $>0.05$ \\
\hline Deaths & $2(3)$ & $0(0)$ & $>0.05$ \\
\hline
\end{tabular}

Data presented as $n$ (\%) unless otherwise indicated. *Range of total length of hospital stay. ICU Intensive care unit; IQR Interquartile range

outcome. The outcome measures selected were mortality, requirement for intensive care, mechanical ventilation, length of stay in hospital and length of stay in the pediatric intensive care unit.

\section{Statistical methods}

Comparisons were made between the pH1N1 influenza and the seasonal influenza cohorts using the Student's $t$ test to assess differences in normally distributed continuous variables, and nonparametric MannWhitney tests were used for comparisons of the skewed length of stay and age data. The $\chi^{2}$ test or Fisher's exact test was used to compare categorical variables between groups and to test for heterogeneity among multiple proportions. Univariate analyses were performed to determine risk factors significantly associated with admission with pH1N1 influenza compared with seasonal inlfuenza; $\mathrm{P}<0.05$ was considered to be statistically significant. Data analysis was conducted using SPSS statistical software (IBM Corporation, USA).

The present study was approved by the Research Ethics Board of the Children's Hospital affiliated with Soochow University and the Research Ethics Board of The Second Hospital of Lanzhou University (Lanzhou, China).

\section{RESULTS}

During the pH1N1 outbreak in the Suzhou region, 75 children were admitted with pH1N1 influenza: the first on September 21, 2009 and the final on January 12, 2010 (Figure 1). During 2008 and 2009, 70 children were admitted with H3N2 and three with seasonal H1N1 between November 1, 2008 and November 1, 2009 (Figure 1). Of note, the pH1N1 epidemic was condensed in time compared with the seasonal H1N1 and H3N2 influenza in the previous year. Two separate peaks for seasonal influenza admission were seen, one in January to March and the other from July to September.

The mean age of those admitted with $\mathrm{pH} 1 \mathrm{~N} 1$ was older, their length of stay was longer than for children admitted with seasonal influenza in the previous year $(\mathrm{P}<0.05)$ and there was a trend 
TABLE 2

Presence of underlying risk factors for hospital and intensive care unit (ICU) admission of children in Suzhou, China, with pandemic (p)H1N1 influenza compared with seasonal influenza A H1N1 or H3N2

\begin{tabular}{|c|c|c|c|c|c|c|}
\hline \multirow[b]{2}{*}{ Risk factor } & \multicolumn{2}{|c|}{ All children admitted to hospital } & \multicolumn{4}{|c|}{ All children admitted to the ICU } \\
\hline & $\begin{array}{c}\text { With pH1N1 } \\
\text { influenza }(n=75)\end{array}$ & $\begin{array}{l}\text { With seasonal } \\
\text { influenza }(n=73)\end{array}$ & $\mathbf{P}$ & $\begin{array}{c}\text { With pH1N1 } \\
\text { influenza }(n=18)\end{array}$ & $\begin{array}{l}\text { With seasonal } \\
\text { influenza }(n=13)\end{array}$ & $\mathbf{P}$ \\
\hline Anemia & $6(8)$ & $0(0)$ & $<0.05$ & $5(28)$ & $0(0)$ & $<0.05$ \\
\hline Cerebral palsy & $2(3)$ & $1(1)$ & $>0.05$ & $2(11)$ & $1(8)$ & $>0.05$ \\
\hline Congenital heart disease & $3(4)$ & $3(4)$ & $>0.05$ & $2(11)$ & $2(15)$ & $>0.05$ \\
\hline Epilepsy & $1(1)$ & $0(0)$ & $>0.05$ & $1(6)$ & $0(0)$ & $>0.05$ \\
\hline Rickets & $2(3)$ & $0(0)$ & $>0.05$ & $2(11)$ & $0(0)$ & $>0.05$ \\
\hline Total & $22(29)^{\star}$ & 11 (15) & $<0.05$ & $13(72)$ & $3(23)$ & $<0.05$ \\
\hline
\end{tabular}

Data presented as $n(\%)$ unless otherwise indicated. *There were 22 underlying conditions; 14 patients had one underlying condition, four patients had two underlying conditions

TABLE 3

Comparison of children hospitalized with first-wave pandemic H1N1 influenza in Suzhou (China), with those in case series from Toronto (Ontario [19]), Argentina (18) and Baltimore (United States [20])

\begin{tabular}{|c|c|c|c|c|}
\hline & Suzhou & Toronto & Argentina & Baltimore \\
\hline$n$ & $75^{*}$ & 58 & 251 & 140 \\
\hline Age, years, median (range) & $3.0(1-6)^{\dagger}$ & $6.4(3.4-10.1)$ & $0.83^{\ddagger}$ & $9.5(0.42-22)$ \\
\hline Intensive care unit admission & $18(24)$ & $12(21)$ & 49 (19) & $13(9)$ \\
\hline $\begin{array}{l}\text { Length of hospital stay, days, median } \\
\text { (interquartile range) }\end{array}$ & $9(8-12)$ & $4(2-7)$ & Not reported & Not reported \\
\hline Underlying condition & $18(24)$ & $46(79)$ & $81 / 241(34)$ & $(92)$ \\
\hline Fatality & $2(3)$ & $0(0)$ & $0(0)$ & $0(0)$ \\
\hline
\end{tabular}

Data presented as $n$ (\%) unless otherwise indicated. *All children were $<14$ years of age; ${ }^{\dagger} 40 \%<2$ years of age; ${ }^{\ddagger} 75 \%<2$ years of age

toward more intensive care and mechanical ventilation requirements (Table 1). A higher percentage of children admitted with pH1N1 had underlying medical conditions known to increase risk for severe influenza compared with admissions for seasonal influenza (24\% pH1N1 versus $11[15 \%]$ seasonal influenza; $\mathrm{P}>0.05$ ) (Table 2 ). Children with pH1N1 influenza were also more likely to have anemia or rickets than children with seasonal influenza $(\mathrm{P}<0.05)$ (Table 2).

There were $23(31 \%)$ pH1N1 cases with secondary bacterial pneumonia compared with $15(21 \%)$ with seasonal influenza $(P>0.05)$ : Streptococcus pneumoniae (13 [17\%] versus 11 [15\%]); Haemophilus influenzae b (4 [5\%] versus 0 [0\%]); Moraxella catarrhalis (3 [4\%] versus $1[1 \%])$; and Staphylococcus aureus (3 [4\%] versus $1[1 \%])$. With seasonal influenza, there were also two cases with Pseudomonas aeruginosa (3\%). All of these patients received antibiotic therapy, which was modified depending on the microbe detected. All patients with pH1N1 also received oseltamivir for five days once hospitalized. None of the children had received $\mathrm{pH} 1 \mathrm{~N} 1$, seasonal influenza, conjugated pneumococcal or $\mathrm{H}$ influenzae $\mathrm{b}$ vaccines.

As shown in Table 2, a slightly higher proportion of the children admitted with pH1N1 (24\%) required intensive care compared with children admitted with seasonal influenza in the previous year (18\%), but this was not significant $(\mathrm{P}>0.05)$. Two of 75 children with $\mathrm{pH} 1 \mathrm{~N} 1$ died from multiorgan failure: one child had a significant underlying congenital heart disease with pulmonary hypertension while the other was a previously healthy boy younger than two years of age. There were no deaths among the 73 children who comprised the seasonal influenza A cohort.

Table 3 provides a comparison of characteristics of the children hospitalized in the first wave of $\mathrm{pH} 1 \mathrm{~N} 1$ in Suzhou with the reported series of pediatric admissions in Toronto (19), Argentina (18) and Baltimore (20).

\section{DISCUSSION}

The major findings in the present case series of 75 children hospitalized with pH1N1 during the pH1N1 outbreak in Suzhou were that these children were older, had longer lengths of stay and that there was a trend toward needing more intensive care and mechanical ventilation compared with the 73 children hospitalized with seasonal influenza A in the preceding year. Neither cohort had high rates of underlying disorders. Thus, some presenting features for $\mathrm{pH} 1 \mathrm{~N} 1$ influenza were similar to those described for children hospitalized with pH1N1 in the United States, Canada and Argentina (11,15,18-20). In Chicago (USA), the highest rate of hospitalization in the first wave of pH1N1 was in children zero to four years of age (11). Similarly, in Argentina, the majority of the children admitted with first-wave pH1N1 were younger than five years of age, with $75 \%$ younger than two years of age, similar to the pattern seen in the Suzhou cohort (18). In contrast, in the series reported from Toronto (19), the majority of children were older than five years of age and the majority of children admitted in the initial wave in the United States were between 10 and 17 years of age $(15,20)$. As well, in the Toronto series and in the American series, the majority had underlying risk factors, $79 \%$ and $60 \%$, respectively, compared with only $24 \%$ in the Suzhou cohort $(19,20)$.

With respect to severity of illness and outcomes of pH1N1, slightly more children in the Suzhou cohort required intensive care $(29 \%)$ compared with $21 \%$ and $18 \%$ in the Toronto (19) and Argentina cohorts (18), respectively, and substantially more than the $9 \%$ in the Baltimore cohort (20). The fatality rates were low in this Chinese pediatric $\mathrm{pH} 1 \mathrm{~N} 1$ cohort $(3 \%)$ and were zero in the other three pediatric cohorts studies $(18-20)$.

Few bacterial coinfections were detected in the first wave in the United States series (15), while the rate in these pediatric patients from the Suzhou cohort was 31\%. This may be an overestimate given that the diagnosis for some of the cases was based on tracheal aspirates. However, only those with positive cultures with an epithelial cell count of $<10$ per low-power field and a leukocyte count of $>25$ per low-power field were considered to be positive. The prominence of both pneumococcal and $H$ influenzae $\mathrm{b}$ coinfections was not surprising because neither pneumococcal nor $H$ influenzae $b$ conjugate vaccines are part of the publicly funded childhood vaccine program in China. During the 1918 pandemic, a large number of deaths were associated with bacterial superinfection (24), but concurrent bacterial infection was not a major factor for severe illness in the present cohort, possibly in part because all of the patients had received antibiotics during their hospitalization. 
Of note, seasonal influenza vaccination is also not part of the routine public vaccine program, but $\mathrm{pH} 1 \mathrm{~N} 1$ vaccine was available although none of those admitted in the present pediatric series had received vaccine before admission. Given the role children, especially school-age children, play in community transmission of influenza $(7-10)$, lack of availability of yearly influenza vaccine may have substantially altered spread and clinical presentation when compared with children in countries where this vaccine is publicly funded and available. Compared with seasonal influenza admissions in Toronto (19), the present Suzhou cohort was younger (median age seven months versus 3.3 years), had longer lengths of stay (seven days versus four days), fewer underlying conditions (24\% versus $73 \%$ ) and had a slightly higher need for intensive care (18\% versus $14 \%$ ).

The variations in findings and outcomes for children hospitalized with seasonal or pH1N1 influenza both within these cohorts and in cohorts from different countries acround the world highlights the ability of influenza to adapt and change with different hosts, ages, presence of underlying conditions, influenza background experiences, and different prevention and treatment regimens. The patterns are quite variable.

A striking finding in the present Suzhou cohort was the prevalence of anemia among the children admitted with pH1N1 influenza compared with those admitted with seasonal influenza ( $8 \%$ versus $0 \%$ ). Anemia was not highlighted in the child admission series from Toronto (19), Argentina (18) and Baltimore (20) but is a recognized presdisposing factor for influenza complications (22). In contrast, asthma was a significant risk factor for $\mathrm{pH} 1 \mathrm{~N} 1$ influenza requiring hospital admission in both the hospitalization series from Toronto (22\%) (19) as well as the case series from Balitmore (85\% with pulmonary disease including asthma) (20). However, in the Suzhou cohort, while asthma was a factor in $\mathrm{pH} 1 \mathrm{~N} 1$ pediatric admissions, the rate was lower $(8 \%)$ and was not different from the children with seasonal influenza (10\%). One potential explanation for the differences maybe different criteria for diagnosing asthma. However, given that Suzhou is located in a highly industrialized area and that asthma is common and well recognized, this seems unlikely. The differences in ages between the Chinese cohort and the North American cohorts possibily explains the differences in the rates of asthma.

Of note, the biphasic (separated double peak) pattern for seasonal influenza A seen in the present study, while not the common pattern in North America or Europe, has been reported in children hospitalized with seasonal influenza in Singapore (17) and in Hong Kong (25). The seasonal double-peak pattern may increase the opportunity for antigenic drift in circulating seasonal influenza strains. The huge population of children in China and the close domestic relationship of many people with birds and pigs may also enhance opportunities for major antigenic shift through interaction with influenza strains circulating in these animals.

The present study of children hospitalized with pH1N1 in Suzhou is limited because the cohort was derived from a single centre, was relatively small in size size $(n=75)$, lacks concurrent community epidemiological data and lacks long-term follow-up for sequelae. However, it is strengthened by having included all positive $\mathrm{pH} 1 \mathrm{~N} 1$ cases and by comparison with children admitted with proven seasonal influenza in the previous year.

\section{CONCLUSION}

The present study of children hospitalized in the first wave of pH1N1 influenza in Suzhou, found differences in presentation, severity and outcomes compared with children hospitalized in North America and Argentina, demonstrating that locale, population influenza experience and the health care system (ie, content of routine childhood vaccine programs) can influence the presentation and outcomes for pandemic and seasonal influenza. However, when compared with the hospitalized cohort with seasonal influenza A in Suzhou, the illness from pH1N1 was only modestly more severe, the age group most affected was only slightly older and there was a trend toward more need for intensive care. Underlying factors were not nearly as prominent a feature as in North American cohorts, and the importance of anemia as a predisposing factor for hospitalization with $\mathrm{pH} 1 \mathrm{~N} 1$ in this age group has not previously been noted. Finally, the gap in the routine vaccinations available for children in China needs to be addressed; influenza, conjugated pneumococcal and conjugated $H$ influenzae $b$ vaccines are not available in China. The prominence of secondary bacterial infections in this cohort highlights, yet again, the need for conjugated bacterial vaccines; a gap previously documented to be linked to serious illnesses and complications in Chinese children $(26,27)$. The influenza vaccine gap also needs to be addressed because the present study showed that even seasonal influenza was a problem in this population.

\section{REFERENCES}

1. Centers for Disease Control and Prevention (CDC). Swine influenza A (H1N1) infection in two children - Southern California, MarchApril 2009. Morb Mortal Wkly Rep 2009;58:400-2.

2. Centers for Disease Control and Prevention (CDC). Outbreak of swine-origin influenza A (H1N1) virus infection Mexico, MarchApril 2009. Morb Mortal Wkly Rep 2009;58:467-70.

3. Editorial Team. Pandemic phase level 4: Human cases of the novel influenza A/H1N1 strain confirmed in Scotland Spain: April 30, 2009. Euro Surveill 2009;14:1-2.

4. New influenza $A(H 1 N 1)$ virus infections: Global surveillance summary, May 2009. Wkly Epidemiol Rec 2009;84:173-9.

5. New influenza A (H1N1) virus - update. Wkly Epidemiol Rec 2009;84:171-2.

6. Public Health Agency of Canada. Flu watch: March 28 to April 3, 2010 (week 13). <www.phac-aspc.gc.ca/fluwatch/09-10/w13_10/ index-eng.php $>$ (Accessed November 30, 2011).

7. Poehling KA, Edwards KM, Weinberg GA, et al. The under recognized burden of influenza in young children. N Engl J Med 2006;355:31-40.

8. Iwane MK, Edwards KM, Szilagyi PG, et al. Population-based surveillance for hospitalizations associated with respiratory syncytial virus, influenza virus, and parainfluenza viruses among young children. Pediatrics 2004;113:1758-64.

9. Bhat N, Wright JG, Broder KR, et al. Influenza-associated deaths among children in the United States, 2003-2004. N Engl J Med 2005;353:2559-67.

10. King JC Jr, Stoddard JJ, Gaglani MJ, et al. Effectiveness of schoolbased influenza vaccination. N Engl J Med 2006;355:2523-32.

11. Centers for Disease Control and Prevention (CDC). 2009 Pandemic Influenza A(H1N1) Virus Infections - Chicago, Illinois, April - July 2009. Morb Mortal Wkly Rep 2009;58:913-8.

12. Perez-Padilla R, de la Rosa-Zamboni D, Ponce de Leon S, et al and INER Working Group on Influenza. Pneumonia and respiratory failure from swine-origin influenza A (H1N1) in Mexico. N Engl J Med 2009;361:680-9.

13. Cutler J, Schleihauf E, Hatchette TF, et al; Nova Scotia Human Swine Influenza Investigation Team. Investigation of the first cases of human-to-human infection with the new swine-origin influenza A (H1N1) virus in Canada. CMAJ 2009;181:159-63.

14. Cao B, Li XW, Mao Y, et al and the National Influenza A Pandemic (H1N1) 2009 Clinical Investigation Group of China. Clinical features of the initial cases of 2009 pandemic influenza A (H1N1) virus infection in China. N Engl J Med 2009;361:2507-17.

15. Jain S, Kamimoto L, Bramley AM, et al and the 2009 Pandemic Influenza A (H1N1) Virus Hospitalizations Investigation Team. Hospitalized patients with 2009 H1N1 influenza in the United States, April-June 2009. N Engl J Med 2009;361:1935-44.

16. ANZIC Influenza Investigators. Critical Services and 2009 H1N1 influenza in Australia and New Zealand. N Engl J Med 2009;361:1925-34

17. Tang JW, Tambyah PA, Lai FY, et al. Differing symptom patterns in pandemic vs seasonal influenza infections. Arch Intern Med 2010;170:861-7.

18. Libster R, Bugna J, Coviello S, et al. Pediatric hospitalizations associated with 2009 pandemic influenza A (H1N1) in Argentina. N Engl J Med 2010;362:45-55. 
19. O'Riordan S, Barton M, Yau Y, Read SE, Allen U, Tran D. Risk factors and outcomes among children admitted to hospital with pandemic H1N1 influenza. CMAJ 2010;182:39-44.

20. Lockman JL, Fischer WA, Perl TM, Valsamakis A, Nichols DG. The critically ill child with novel H1N1 influenza A: A case series. Peds Crit Care Med 2010;11:173-8.

21. Bernard G, Artigas A, Brigham K, et al and The Consensus Committee. Report of the American-European consensus conference on ARDS. Definition, mechanisms, relevant outcomes and clinical trial coordination. The Consensus Committee. Intensive Care Med 1994;20:225-32.

22. National Advisory Committee on Immunization. Influenza Vaccine in the Canadian Immunization Guide, 7th edn, 2006; 209-220.23. Taylor CE, Camargo CA Jr. Impact of micronutrients on respiratory infections. Nutr Rev 2011;69:259-69.
24. Morens DM, Taubenberger JK, Fauci AS. Predominant role of bacterial pneumonia as a cause of death in pandemic influenza: Implications for pandemic influenza preparedness. J Infect Dis 2008; 198:962-70.

25. Chiu SS, Chan KH, Chen H, et al. Virologically confirmed population-based burden of hospitalization caused by influenza $\mathrm{A}$ and $\mathrm{B}$ among children in Hong Kong. Clin Infect Dis 2009;49:1016-21.

26. Zhang QL, Wan CM, MacDonald NE. Vaccine preventable infections and multiple organ dysfunction syndrome in critically ill children in China. Pediatr Infect Dis J 2009;28:182-5.

27. Zhang Q, Guo Z, MacDonald NE. Vaccine preventable communityacquired pneumonia in hospitalized children in Northwest China. Pediatr Infect Dis J 2011;30:7-10. 


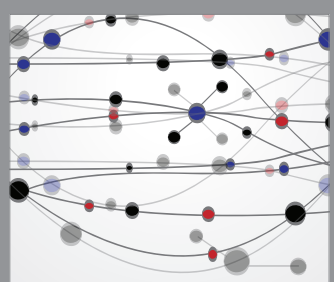

The Scientific World Journal
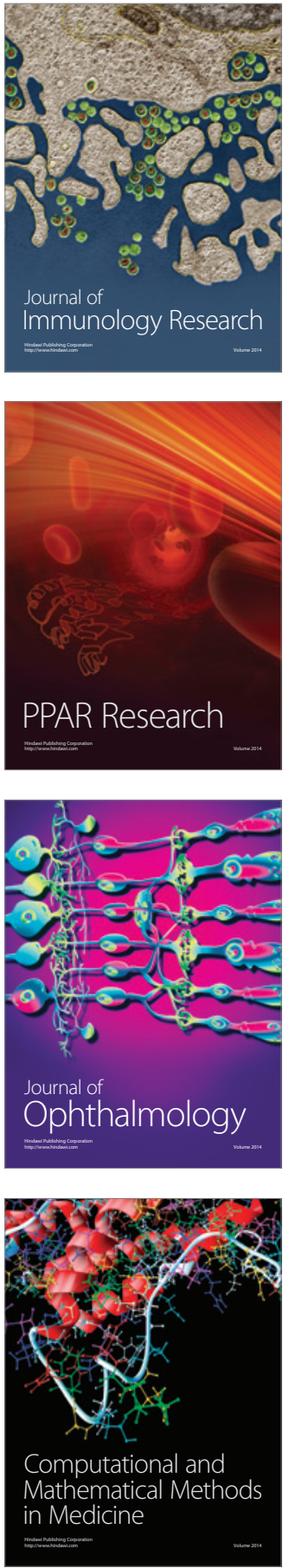

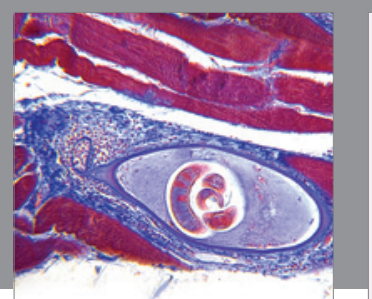

Gastroenterology Research and Practice

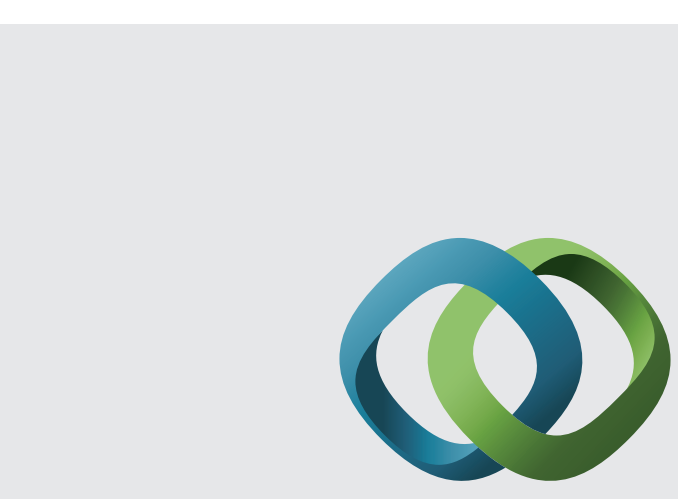

\section{Hindawi}

Submit your manuscripts at

http://www.hindawi.com
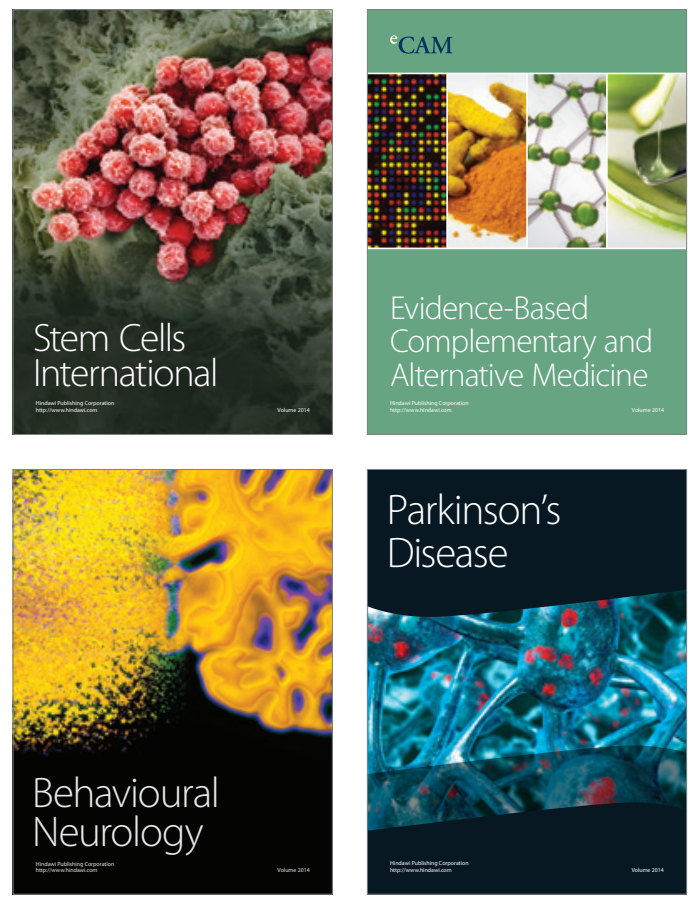
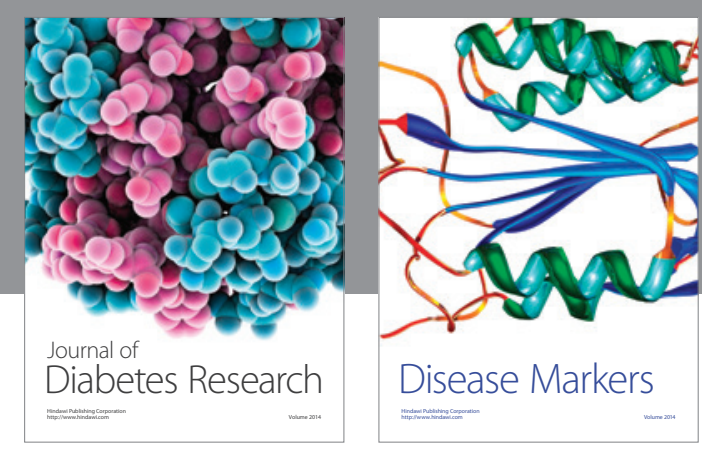

Disease Markers
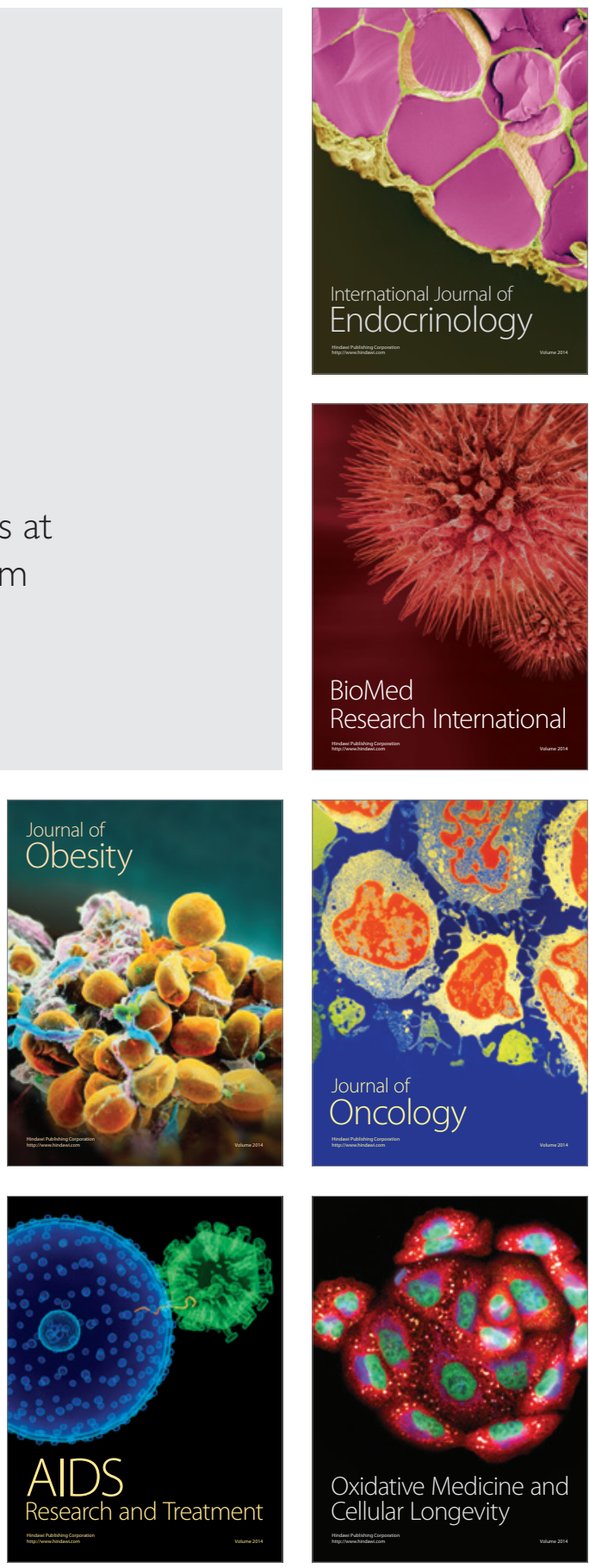